\title{
الادارة بتمكين العاملين وأثرها على الأداء الوظيفي لاى العاملين بحمامات السباحة فى محافظة اسوان
}

"أ. أد/ عادل محمد عبد المنعم مكى

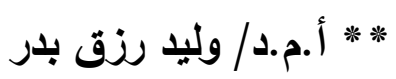

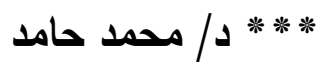

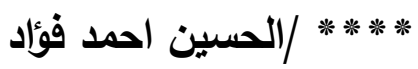

\section{المقدمة ومشكلة البحث :}

يعـيش الجميـع مـع بدايـة القـرن الحـادي والعشـرين وسـط متغيـرات وتحديات عديدة ومتلاحقة في شتى مجالات الحياة، فمعلات التغيير في تزايد مستمر والأعمال تتوجه بصورة ملحوظة إلى العالمية وفى كل يوم تزداد ظهور التكنولوجيا الجديدة المنطورة والقوى العاملـة تصبح أكثر تتوعاً من حيث المعرفة والمهارة.(· (:7 (1) وتعتبر الإدارة هي المسئولة عن نجاح أي نشاط وهي التي تؤدي إلى تقدم أو تخلف أي نشاط والتي يمكن عن طريقها تحقيق أهداف أى منظمة من المنظمات أو أي مجتمع من المجتمعات. ( r:IV ) ويعتبر تمكين العاملين هو الصيحة التي تتردد مؤخراً فى مجال تطور

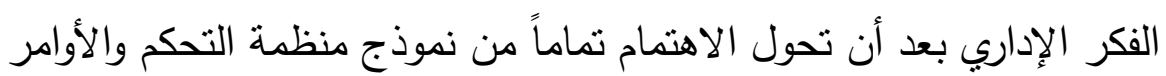

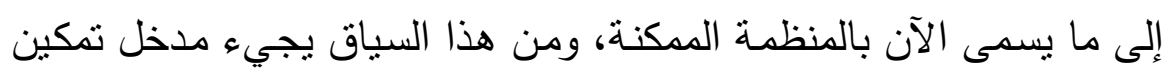

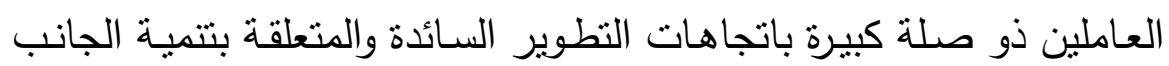
الإنسانى داخل المنظمة، فتمكين العاملين يعد من الموضوعات التي برزت بـات

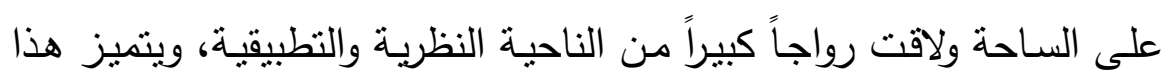


المدخل بفلسفة جديدة قوامها ألا يكون تركيز المدير على التتظيمات داخل المؤسسة وإنما على العاملين فى المقام الأول. (r ( 9 ( )

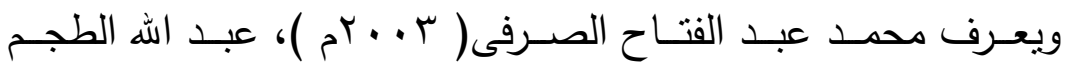

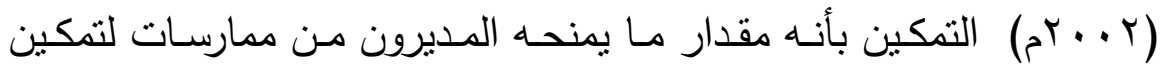

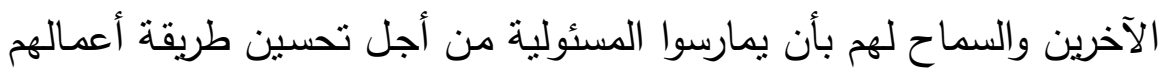

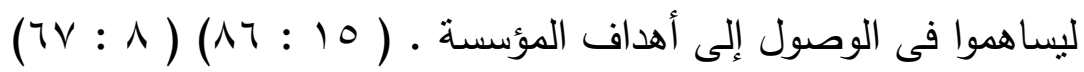

وترى "خولة خميس عبيد" (T . .r م ) أن التمكين هو مكون تحفيزي

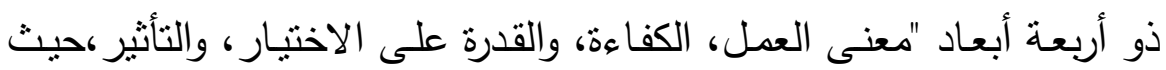
تؤهل العاملين لامتلاك قدرات مستقلة تمكنهم من اتخاذ القرار بما يتتاسب مع أهداف المنظمة. $(\wedge 9: 4)$

* أستاذ الإدارة الرياضية و عميد كلية التربية الرياضية ـ كلية التربية الرياضية ـ جامعة اسوان

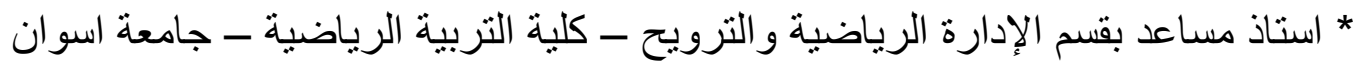

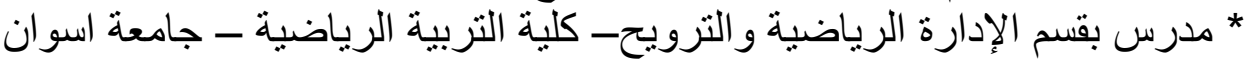

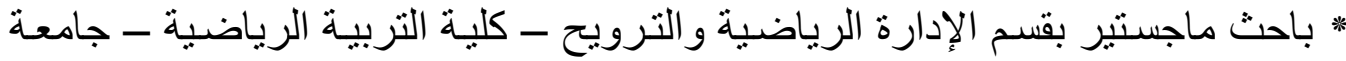
اسوان 
ويعد مصطلح التمكين من المصطلحات الحديثة في علم الأدارة التي حظيت باهتمام المنظمات والمديرين وهو يعبر عن عملية إعطاء الفرد سلطة أوسـع في ممارسـة الرقابـة وتحمـل المسؤولية وفي استخدام قدراتهز ، ومـن خلال تشجيعهم على اتخاذ القرار بمعناه الواسع لذا فإن هذا المنظور يثير الى المشاركة بين العاملين والادارة العليا في أربعة عناصر أساسية هي ( المعلومات عن المنظمـة، والمعرفـة التي تسـاعد العاملين على فهم إعمالهم والمسـاهمة في الأداء الكلي للمنظمـة، بالاضـافة الى المكافآت والتي تحدد على أسـاس اداء المنظمـة، واخيرا إتخاذ القرارات التي تؤئز في اداء واتجـاة المنظمة

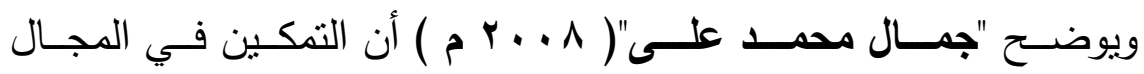
الرياضـي يقصــــــه جعـل العـاملين في المجـال الرياضـي قـادرين على وضـع

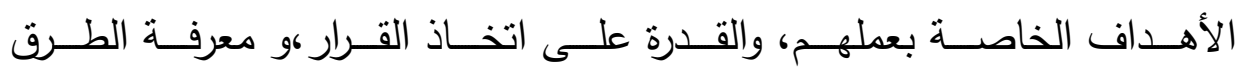
العلميــة لحـل المشـكلات فـي المجـال الرياضــي وذلـك فـي نطـاق مسـؤليتهم

$$
\text { وسلطاتهم· (r: (1) (1) }
$$

ويعتبـر التمكين سياسـة مـن سياسـات التحفيز والتشـجيع فهو ثقافـة تتظيمية تقوم على إعطاء العاملين صلاحيات ومسؤليات وحرية أداء الأعمال بالأسـاليب المناسـبة لهم دون تـدخل مباشـر مـن الإدارة مـع تـوفير المنـاخ

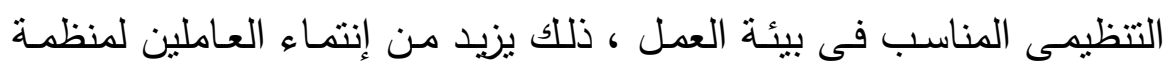

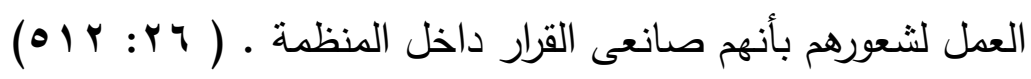

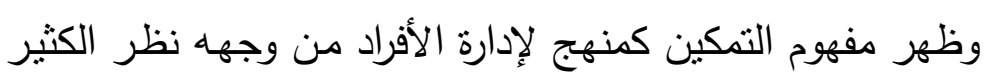

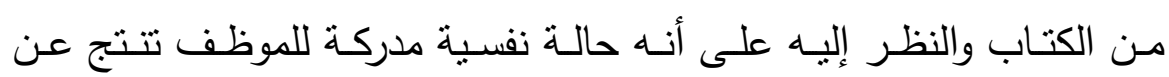


التمكين الذى يقدمه المشرف ، وأنـه سلوك المشرف الذى بمكن مرؤوسيه و

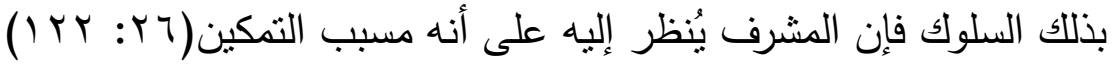
وتسـى الهيئـات الرياضـية إلى تحقيـق هدف مـزدوج هـو زيـادة أداء العاملين وتحقيق رضـا الجميع، حيث يعتبر الأداء الجيد هو وسيلة للتقدم والارتقاء بمسنوى هذه الهيئات الرياضية. (T:IV) فالأداء الوظيفي هو قدرة الإدارة على تحويل المدخلات الخاصة بالتظيم إلى عدد من المخرجات بمواصفات محددة وبأقل تكلفة ممكنة $(01: 17)$.

ويعد الأداء الوظيفي هو أهم محاور فاعليـة الأداء الكلى للمنظمـة، وذلك يتطلب ضـرورة اهتمـام واعتتـاء كافـة المديرين في جميع المسـتوبات التتظيميـة بتطوير وتتميـة أداء المرؤوسين من حيث الكميـة والجودة حيث يـعكس ذلـك بالضـرورة على أداء جماعـات العمـل والنتيجـة أو المحصـلة النهائية هي فاعلية أداء المنظمة ككل. (ع ب: ؟1 - . 9)

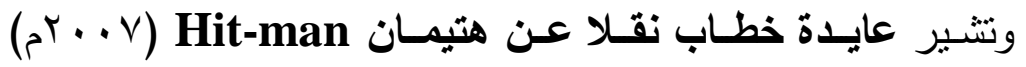
وآخرون أن الأداء الوظيفى المبنى على الرضـا الوظيفي هو تعبير يطلق هن هن على مشاعر العاملين تجاه أعمالهم وهذه المشـاعر تعتمد على ادرأ كين :

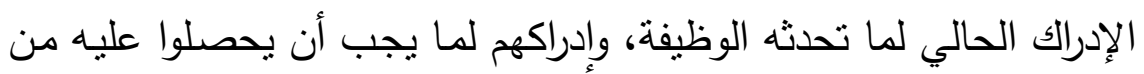
هذه الوظيفة وكلما انخفضت الفروق بين ما يحصل عليه الفرد فعلا وبين ما يتوقع أن يحصل عليه فان الرضا الوظيفي يرتفع والعكس صحيح ( ^: 
وهنالك العديد من العوامل التي تساهم في التأثير على الأداء

الوظيفي للأفراد في وظائفهم منها مـا هو متعلق بالفرد نفسـه مثل (السن،

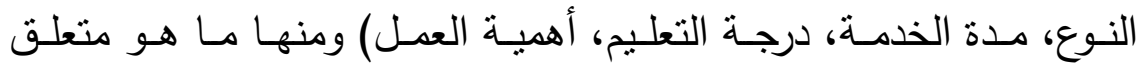
بالوظيفة مثل (السيطرة على الوظيفة، شعور الفرد بالإنجاز في الوظيفة، مدى استغلال الفرد لقراته، المشاركة في اتخاذ القرار ، زمن الترقي، الأجر والحـوافز، العلاقـات مـع الآخـرين، ومنهـا مـا هـو متعلـق بالمنظمـة مثنل

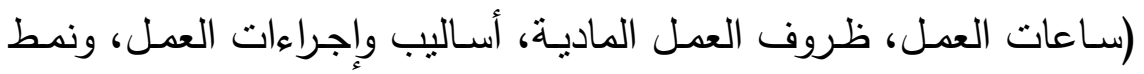
الإشراف) وأخيراً العوامل المتعلقة بالبيئة الخارجية مثل (الرضـا عن الحياة) نظرة المجتمع للموظف، الانتماء الديموجرافى. (9V: (Y)

كما يعتبر من أهم محددات الأداء الوظيفي (الجهد، القدرات)، إدراك الدور المهام و"الجهد" هو الناتج من حصول الفرد على التدعيم الحوافز إلى الطاقة الجسمانية والعقلية، والتي يبذلها الفرد لأداء مهنته، أما "القدرات" فهي الخصائص الشخصية المستخدمة لأداء الوظيفة، ولا تتغير وتثقلب هذه القدرات عبر فترة زمنية قصيرة، ويشير "ادارك الدور أو المهمة" إلى الاتجاه الذي يعتقد الفرد أنه من الضروري توجيه جهوده في العمل من خلالهه، وتقوم الأنشطة والسلوك الذي يعتقد الفرد بأهميتها في أداء مهامه بتعريف إدراك

$$
\text { الدور • ( ) ( }
$$

وبعد المجال الرياضـي من أهم مجالات الاستثمار الحقيقي للثروة

البشرية حيث يحوى العديد من العمليات التربويـة ذات الاتجاهات والجوانب المنتعبة والتي تهدف إلى تربية الأجيال لإثراء كل مجالات الحياة، ويتميز

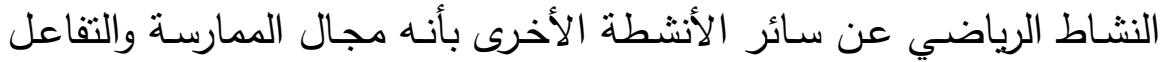


الذي يدور حول تعديل السـوك للكائن البشـرى وإعداد المـواطن الصـالح • (ro: 10$)$

وتعتبر الرياضات المائية شكل من أشكال الرياضة فهي مجموعة من الأنشطة يجمع بينهما إستخدام الوسط المائى،حيث تعتمد عليه إعتماداً كلياً وتعتبر الرياضيات المائية من أكثر الرياضيات المحببة للإفراد ليس فى الوطن العربى ولا مصر فقط بل وفى دول العالم بأثنه نظراً لما تتمتع به فى عنصرالنتويق والإثارة. (r) (1)

ولذلك احتلت حمامات السباحة مكاناً هاماً فى حياة الافراد والجماعات خاصةً فى المدن الكبرى والبلاد المتقدمة، حيث يتردد عليها الكثير من الناس من مختلف الأعمار لممارسة تلك الهواية المحببة إلى النفوس لإثباع رغباتهم مما دعا إلى زيادة عددها وما تبع ذلك من ضرورة توجيه الاهتمام بها والرقابة الدائمة عليها ومراعاة الشروط والمواصفات الخاصة بعوامل الأمن والسلامة فى حمامات السباحة، حتى لا تتسبب في الضرر للمستفيدين.

وتعتبر حمامات السباحة ذات اهمية بالغة فى ممارسة الانشطة الترويحية والتعليمية والتدريبية للرياضات المائية للإرتقاء بمستوى السباحين لتحقيق بطولات أولمبية ودولية من خلال جودة الخدمات المقدمة بحمامات السباحة، لذلك فإن الدولة تولى اهتماماً خاصاً لزيادة أعداد حمامات السباحة والارتقاء بها ودعمها مادياً لتطويرها وتحسين طرق الأداء فيها بما يكفل الوصول إلى الهدف المنشود من إنشائها. (1) 
ومن خلال العرض السابق يتضح للباحث أهمية دور تمكين العاملين على الاداء الوظيفي للعاملين الذي ينعكس على المفاهيم التى تتعلق بالفرد

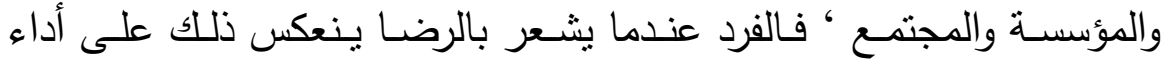
عمله فيؤديه بنجاح وينعكس كذلك على جوانب حياته الأسرية والاجتماعية فيشعر بالسعادة والنجاح ، والمؤسسة التي يكون موظفوها راضيين عن أدائهم الوظيفي تتمتع بالاستقرار ل

والقدرة على تحقيق مستويات إنتاجية عالية والمجتمع الذي يكون أفراده راضيين عن أدائهم الوظيفي وجوانب حياتهم الأخرى يكون مجتمعا متقدما

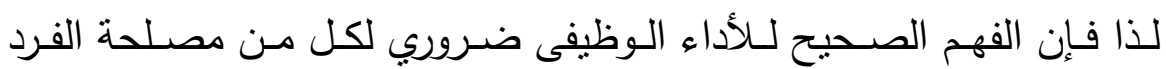
والمؤسسة والمجتمع ، فالاداء الوظيفى في المؤسسـات الرياضية بشكل عام ولدى العاملين بحمامات السباحة داخل هذه المنشآت على وجه خاص له اثر لثر له بالغ على الحالة التى عليها المؤسسة او حمام السباحة.

ومـن خـلال عمـل الباحث في مجـال السباحة وأدارة حمامـات السباحة لاحظ الباحث أن هناك قصور في إدراة العاملين بحمامات السباحة لمدى تحديد علاقة وظيفتهم بالهدف العام للمؤسسات أو الهيئة التي بعملون إنراهن بها وذلك بسبب ضعف مشاركتهم في اتخاذ القرارات المتعلقة بوظائفهم وعدم اقتتاع الإدارة العليا بهذه المؤسسات بقدرة المرؤوسين (العاملين) بحمامـات السباحة على اتخاذ القرارات المناسبة والتي تحقق النتائج المطلوبـة دون أي لإداني أخطاء وذلك لتخوفهم من فقد السلطة التي يتمتعون بها. 
وتظهر أهميـة هذا البحث في الاهتمـام بـالأفراد العـاملين بحمامـات

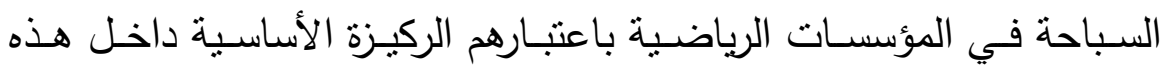

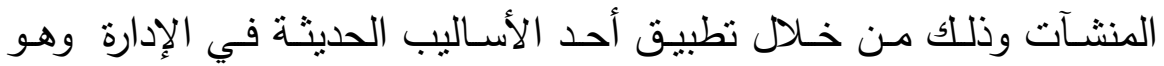
تمكين العاملين الذي يقوم على مشاركة العاملين في اتخاذ القرارات ومنحهم النفـوذ والسـلطة والقـوة وتحمـل المســولية فـي القـرارات التـي يتخـذونها أو يشـاركون فيهـا مـع الإدارة العليـا و الانتمــاء والارتيـاح لإتــباع الحاجـات

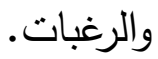

ومن خلال عمل الباحث فى مجال الادارة بحمامـات السباحة لاحظ إعتماد حمامات السباحة فى العمل على إتجاهات إدارية تقليدية، كما لاحظ الباحث عدم إيمان الأدارة العليا بحمامات السباحة بقدرات ومهارات العاملين بتلك المؤسسـات الأمـر الذي يظهر في عدم تفويض قدر من الصـلاحيات

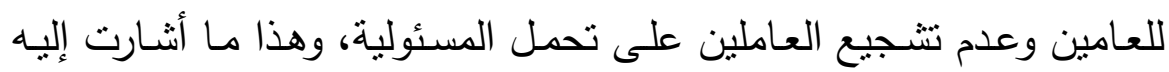

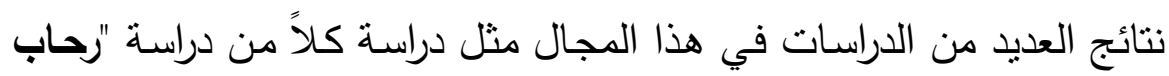

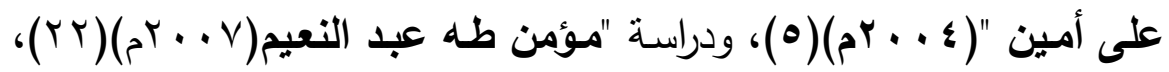
والتي أجريت فى مجال حمامات السباحة والتى كانت من أهم نتائجها أن الاعتماد على الإتجاهات الإدارية التقليدية تؤدى إلى ضعف الأداء الإدارى بحمامات السباحة والآداء الوظيفى للعاملين بها مما يقلل من فاعلية الإنجاز

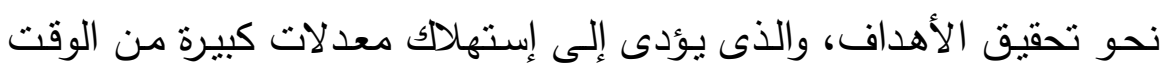

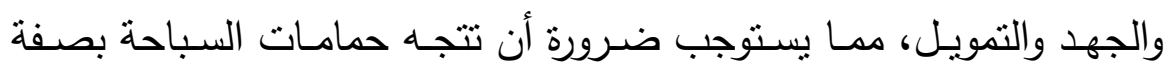

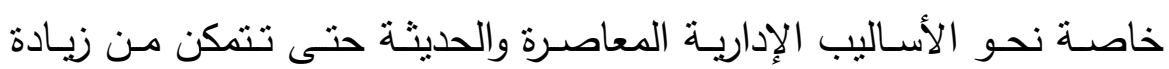
الفاعلية وتحقيق أعلى مستوى ممكن من الإنجاز على مختلف المستويات المحلية والدولية. 
ويرى الباحث أنه بالرغم من اهتمام الدراسات الحديثة بموضوع تمكين العـاملين باعتبـاره أحـثث المـداخل الرئيسـية للإصــلاح الإداري في في الـدول

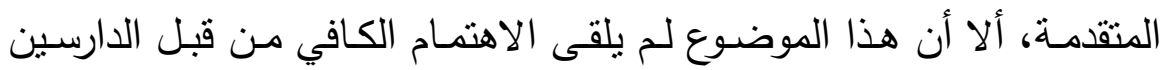

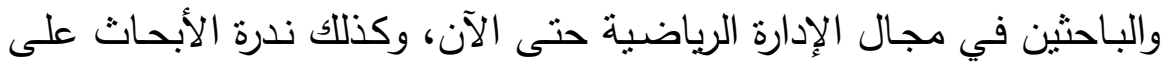

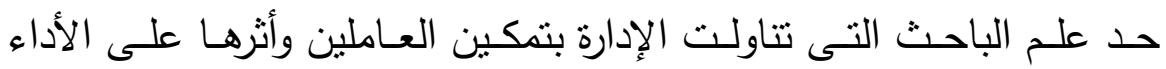
الوظيفي للعاملين بحمامات السباحة في المؤسسات الرياضية بشكلا عام وفى لهى محافظة اسوان بشكل خـاص وهذا مـا دفع الباحث للسعى الى القيام بهذه الدراسة.

\section{أهمية البحث والحاجة إليه :}

1 - على حد علم الباحث إن المكتبة العربية تفتقر لإسهامات الباحثين فى مجال التمكين للعاملين، حيث لاحظ الباحث من خلال تقصيه الدراسات العربية ندرة هذه الدراسات فى هذا المجال. r- قد يأتي هذا البحث دعماً لغيره من الدراسات السابقة ويضيف إليها دراسة متخصصة فى الإدارة الرياضية.

r- قد يكون هذا البحث إحدى المحاولات العلمية التى تساعد في زيادة فاعلية الأداء الوظيفى لدى العاملين بحمامات السباحة. ع - توجهه أنظار القائمين فى المجال الرياضي إلى أستخدام التمكين الإداري لما قد يكون له أثز واضح في زيادة فاعلية الأداء الوظيفى لدى العاملين بالمنظمات الرياضة المختلفة وحمامات السباحة بصفة خاصة. 0ـ قد يساهم هذا البحث فى الإثراء الفكرى لموضوع التمكين الإداري وزيادة فاعلية الأداء الوظيفى · 


\section{هدف البحث :}

يهرف البحث التعرف على أثر تمكين العاملين على الأداء الوظيفي

لاى العاملين في إدارة حمامات السباحة بمحافظة اسوان وذلك من خلال:

1- تحديد أبعاد تمكين العاملين بحمامـات السباحة في المؤسسات

$$
\text { الرباضية بمحافظة اسوان }
$$

r- مـدى العلاقـة بـين أبعـاد تمكين والأداء الـوظيفي لـدى العـاملين

بحمامات السباحة بالمؤسسات الرياضية بمحافظة اسوان المان لمنين

$$
\text { تساؤلات البحث : }
$$

ا ـ مـا درجـة توافر أبعـاد تمكين العـلين بحمامـات السباحة فى المؤسسـات

الرياضية؟

r. مـا الواقع الحالي للأداء الوظيفي للعاملين بحمامات السباحة في

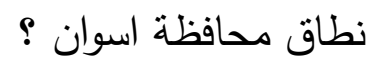

r. ما النموذج المقترح لتمكين العاملين لزيادة فاعلية الأداء الوظيفي

للعاملين بحمامات السباحة في نطاق محافظة اسوان ؟

$$
\text { المصطلحات المستخدمة في البحث : }
$$

$$
\text { التمكين : (التمبن }
$$

هو عملية لتعزيز الإحساس بالإندماج الوظيفى والإبتعاد عن الإحساس بالعزلـة و الإعتمـاد على الذات من خـلال تحديد الظروف التى تمنـح القوة

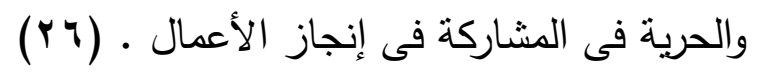




\section{تعريف اخر :}

هو عملية نقل المسؤولية والسلطة بشكل متكـافئ مـن المـيرين إلى المرؤوسين وفي التمكين يكون المرؤوس الممكن مسؤولاً عن جودة ما يقرره أو يؤديه، ويتضمن إعطاء السلطة للمرؤوسين لاختيار سبل تتفيذ المهام

$$
\cdot(1 \leqslant \Lambda: 9)
$$

\section{Functionality: الأداء الوظيفي}

قدرة الفرد على تحقيق المهام والأعمال المحددة لـه مسبقاً في الوقت

$$
\begin{aligned}
& \text { المحدد وبالطريقة الملائمة لها بنجاح. (ع : بr) } \\
& \text { تعريف اخر : }
\end{aligned}
$$

هو قدرة الإدارة على تحويل المدخلات الخاصـة بالتتظيم إلى عدد من

$$
\begin{aligned}
& \text { المخرجات بمواصفات محددة وبأقل تكلفة ممكنة (7 (: (0) } \\
& \text { الاراسات السابقة : }
\end{aligned}
$$

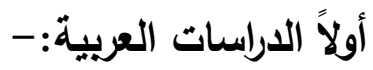

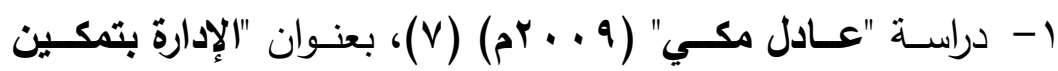

العـلين وأثرهـا على الرضـا الـوظيفي بحمامـات السباحة في المؤسسـات

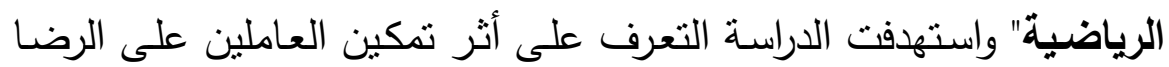
الوظيفي لدي العاملين في إدارة حمامات السباحة، واستخدم الباحث المنهج

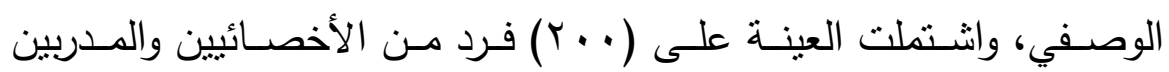

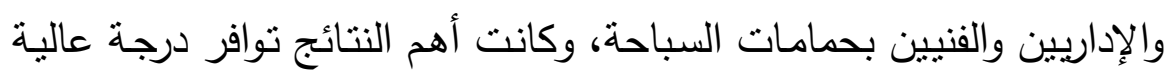
من أبعاد التمكين للعاملين بحمامات السباحة في المؤسسات الرياضية، ويعد

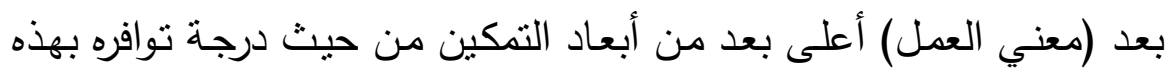
المؤسسات. 


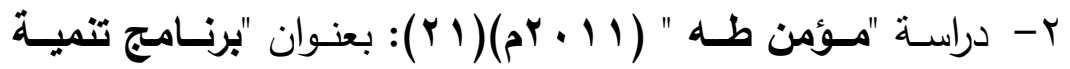
إداريـة للعـاملين بحمامـات السـباحة في ضـوء التحليـل الـوظيفي والقـدرة التسويقية التنافسية"، واستهدفت الدراسة تصميم برنامج تتمية إدارية للعاملين بحمامات السباحة في ضوء التحليل الوظيفي والقدرة التسويقية التنافسية وذلك مـن خـلال التحليـل الـوظيفي للعـاملين بحمامـات السـباحة وتحليـل القـدرة التسـويقية التنافسية بحمامـات السـباحة، واسـتخدم الباحث المنهج الوصـفي والتجريبـي، وتم اختيـار مجتمـع البحث مـن المسـتفيدين ومقدمي الخدمات بحمامات السباحة بواقع 9 r حمام سباحة من المستقيدين و 9 rحمام سباحة من مقدمي الخدمات، وكانت أهم النتائج عدم وجود توصيف وظيفي محدد وواضـح للعـاملين بحمامـات السـباحة وتحقق ثلاثـة عشـرة وظيفيـة للعـاملين بحمامات السباحة.

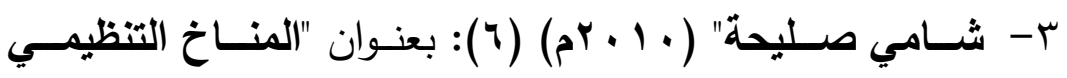
وتـأثثيره علـي الأداء الـوظيفي للعـاملين " واسـتهدفت الدراسـة التعرف علي التي المنـاخ التنظيمسي وتـأثيره علي الأداء الـوظيفي للعـاملين، واسـتخدم الباحـث المنهج الوصفي، وتم اختيار عينة الدراسة من الإتحاد المصري لتسس الطاولة

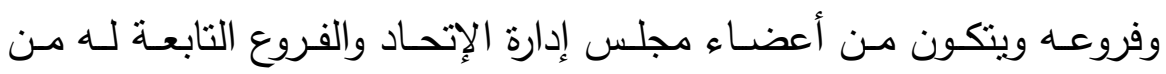

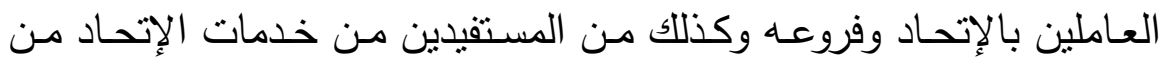

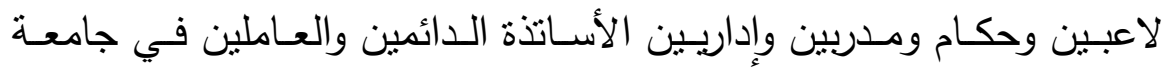

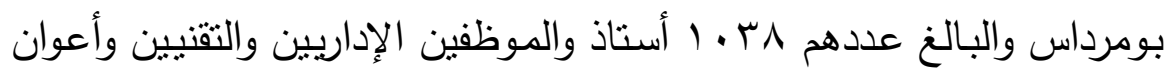
المصالح الدائمين والبالغ عددهم اسل ل موظف، 
وكانـت أهـ النتائج أنـه هنـاك شـعور محايد أو معتدل لـدى معظم الموظفين الإداريين على المناخ التنظيمي السائد وهناك تصور سلبي لاى معظم الأساتذة على المناخ التتظيمي.

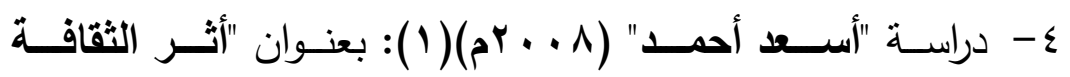
التنظيميـة على مسـتوى الأداء الـوظيفي"، واستهدفت الدراسـة أثنر التقافـة

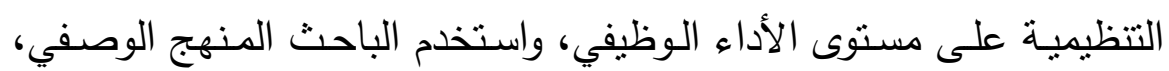

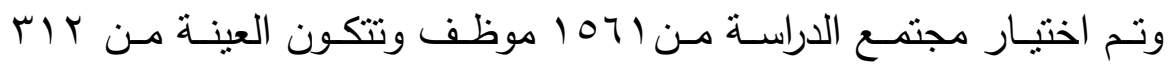

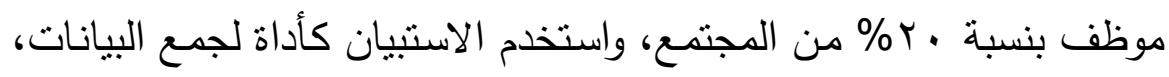
وكانت أهم النتائج أنه هناك اثر ايجابي للتقافة التتظيمية على مستوى الأداء الوظيفي وأظهرت الدراسـة إن العاملين بحاجـة إلى تطوير مستوى المهارات والقدرات المتعلقة بالجوانب الإبداعية والإبتكارية.

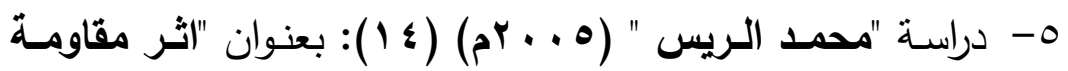
التغيير على فاعليـة الأداء الـوظيفي بـالتطبيق على شـركة العين لتوزيـع

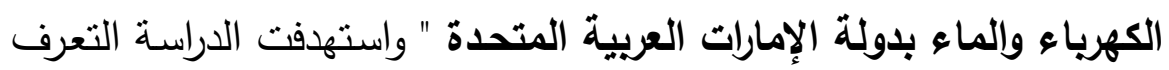
على العوامل التي تدعو إلى التغيير والتعرف على الأسباب التي تؤدى إلى التى مقاومـة التغييـر والتعـرف على الأسـباب التـي تـؤدى إلـى مقاومــة التغييـر

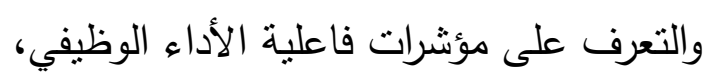

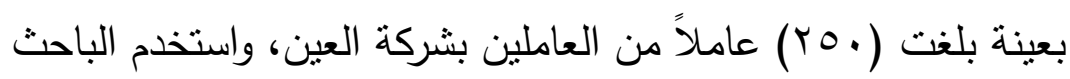

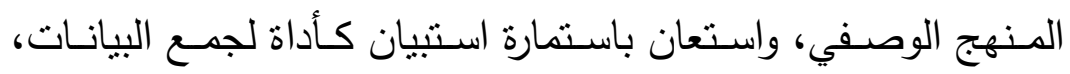

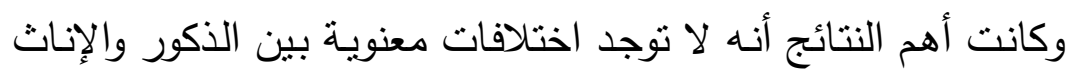

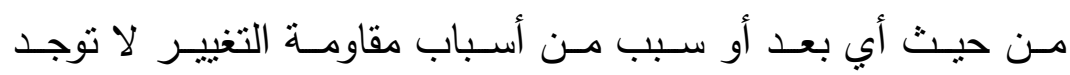

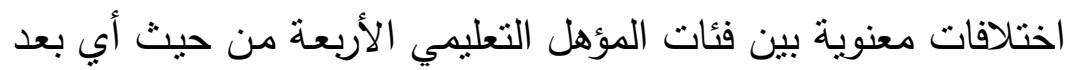
أو سبب من أسباب مقاومـة التغيير، كما توجد علاقة ارتباط عكسية 
معنوية بين كل سبب من أسباب مقاومة التغيير وبين كل مؤشر من مؤشرات فاعلية الأداء الوظيفي الخمسة.

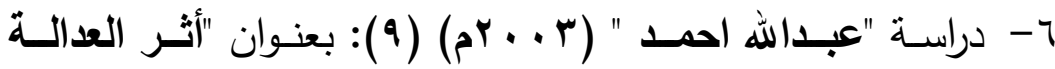
التظظيميـة على فاعليـة الأداء الـوظيفي (بـالتطبيق على أعضى أعـاء هيئة التدريس بجامعة الكويت) "واستهدفت الدراسة التعرف على التعريف بمفهوم العدالـة التظظيميـة وأبعادهـا المختلفـة وأهميتها ودراسـة مفهوم الأداء الوظيفي ومفهوم فاعليـة الأداء الـوظيفي مــع شـرح مؤشـرات فاعليـة الأداء الـوظيفي،

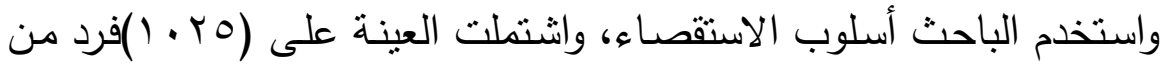

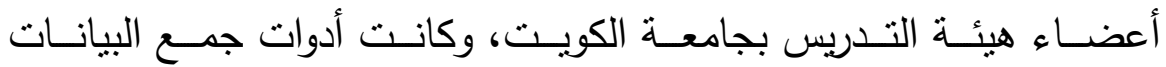
الاستقصاء، وكانت أهم النتائج أن مقياس العدالة التتظيمية هو مقياس يقوم على هيكل واحد وان الإلمام الوظيفي لأعضاء هيئة التدريس بجامعة الكويت يتأثز معنوياً بأحد أبعاد العدالة التنظيمية.

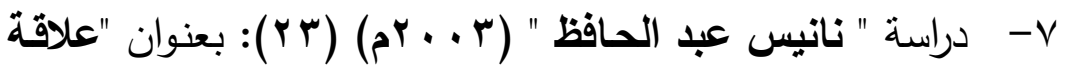
ضـغوط العمـل بفاعليـة الأداء الـوظيفي للمـرأة العاملـة" واستـهدفت الدراسـة

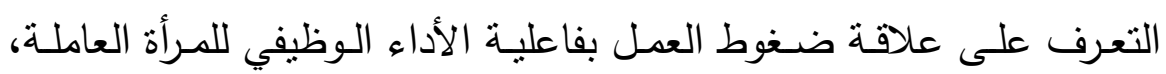
بعينة بلغت ( ـ ) وهم العاملات بمستشفيات جامعة عين شمس،واستخدمت

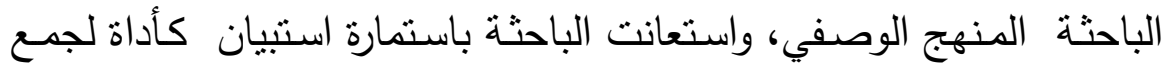

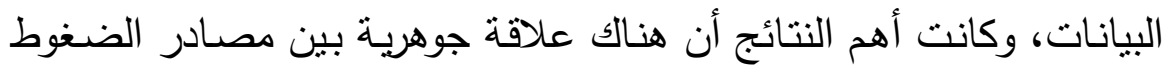
وفاعليـة الأداء الوظيفي للمرأة العاملـة، كما أن مستوى فاعليـة الأداء للمـرأة العاملـة يزيد عن المتوسط، كما تبين وجود اختلافـات جوهريـة في الأهميـة النسبية لمصادر ضغوط العمل.

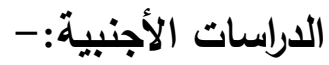




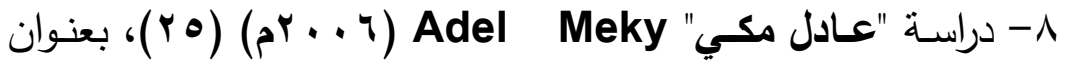

Ways of marketing of the water sport in the Arab Republic of Egypt" الدراسة دراسـة أسـاليب تسويق الرياضـات المائية في جمهوريـة مصر العربية، ووضـع تصـور مقترح لتسـويق رباضـة الثـراع والغـوص، واسـتخدم الباحث المنهج الوصفي، واشتملت العينة على (• ع) عضو من أعضاء مجلس إدارة اتحاد الشراع والغوص، وكانت أهم النتائج استخدام الأساليب العلمية الحديثة يساعد في عملية تسويق الرياضات المائية في جمهورية مصر العربية.

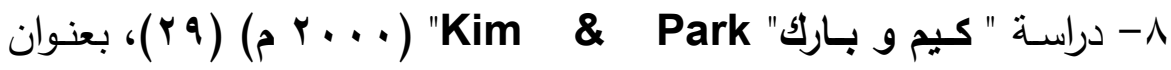
Integrating Distinctive Manufacturing Competence تأثير "Globally: Its Effect on Business Performance" التسيق والتكامل في أداء الأعمال على التتافس بين الثركات العالمية"، واستهدفت الدارسة التعرف على مدي تأثنر التتسيق والتكامل بين القدرات الإنتاجيـة المختلفـة في فاعليـة الأداء بالثـركات متعـددة الجنسيات التي ملي

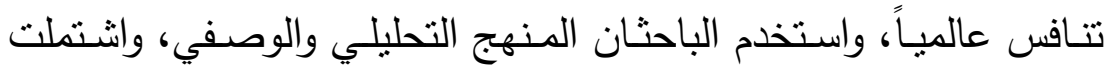
عينة الدراسـة على آ شـركة، وكانت أهم النتائج أن مستوى المهارات والخبرات لدي العاملين وسهولة انتقال المديرين أمثر تكاملاً ولها تأثثر معنوى في تحقيق الفاعلية وذات ارتباط معنوي طردي بالأداء.

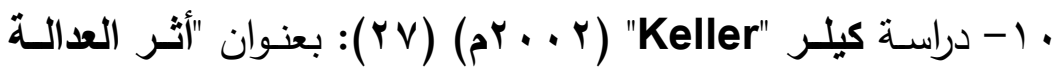
التنظيمية في الرضا الوظيفي للعاملين"، استهدفت هذه الدراسـة دراسـة الأثر الذي قد تحدثه العدالة التظظيميـة في الرضـا الوظيفي للعـاملين، وهل للنوع 
والمستوى التتظيمي أثر في إدراك العاملين للعدالة التتظيمية ببعديها، بعينـة

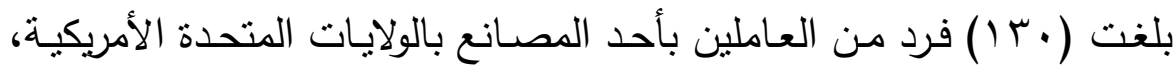
واستخدم الباحث المنهج الوصفي، وكانت أهم النتائج أن العدالة التنظيميـة تؤثز تأثيراً طردياً في الرضا الوظيفي. خطة واجراءات البحث:-

$$
\text { منهج البحث: }
$$

سوف يستخدم الباحث المنهج الوصفي (الدراسـات المسحية) لملائمته

$$
\text { لطبيعة وأهداف البحث. }
$$

يتمثل مجتمـع البحث في العاملين بحمامـات السباحة بنطاق محافظة

$$
\text { عينة البحث: }
$$

يسـتخدم الباحث الطريقة العشـوائية مـن مجتمـع البحث مـن العـاملين بحمامات السباحة بمحافظة اسوان وعددهم بواقع ( • ) فرد المؤسسات وتم اختيارهم بالطريقة العشوائية الطبقية.

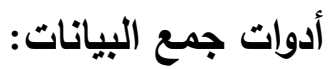

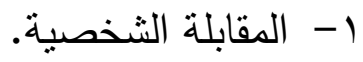

r- تحليل الدراسات والمراجع العلمية المرتبطة بموضوع البحث. 


\section{الأستبيان ويشتمل على :-}

ا ـ أستبيان للتعرف على الواقع الحالي لممارسة التمكين للعاملين محافظة اسوان بحمامات السباحة في

r. أسـتبيان للتعـرف على الواقـع الحـالي لـلأذاء الـوظيفي للعـاملين محافظة اسوان. بحمامات السباحة في

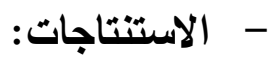

1 - قد يتوافر درجـة عالية مـن أبعاد التمكين للعاملين بحمامات السباحة في المؤسسات الرياضية بنطاق محافظة اسوان. r - قد يكون ثرتيب حمامات السباحة بالمؤسسات الرياضية وفقاً لدرجة الاداء الوظيفي يتفق إلى حد ما مع ترتيبهم وفقاً لمدى توافر أبعاد تمكين العاملين. ب- قد توجد علاقـة ارتباطيـه جوهريـة ببين أبعاد تمكين العاملين الثلاثـة وهم

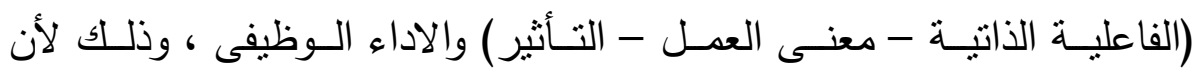

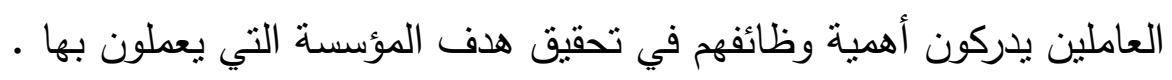
ع- يستتتج الباحث أنـه لكي يتم التطبيق الناجح للتمكين العـاملين بحمامـات السباحة بمحافظة اسوان بالمؤسسات الرياضية لابد من توفير الدعم المادي

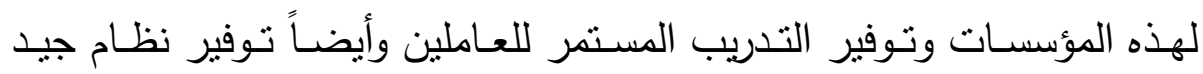
للحوافز والمكافآت لتشجيع العاملين على بذل الجهر والتحسين المستمر للأعمال والخدمات لكي تسنطيع هذه المؤسسات تحقيق الهدف الذي أنشئت من أجله. 
في ضوء أهداف البحث وفى حدود مجتمع وعينة البحث المختارة وفى ضوء الاستتناجات السابق عرضها فيإنه يمكن صياغة وعرض التوصيات الآتية: 1- يوصسى الباحـث الإدارة العليـا بحمامـات السباحة بالمؤسسـات الرياضـية

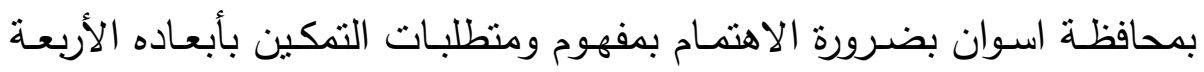
حيث يعتقد الباحث بقوة تأثيرهم إلى حد ما على الاداء الوظيفي لدى العاملين بحمامات السباحة في المؤسسات الرياضية بمحافظة اسوان والعمل على نشر مفهوم التمكين في هذه المؤسسات.

ץ- التأكيد على جماعيـة العهـل وروح الفربـق والنظـر إلـى عملهم وتحقيـق

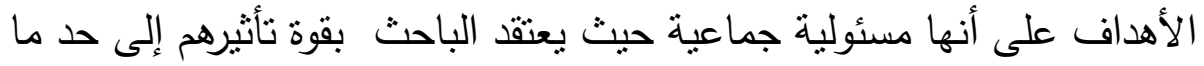
على الاداء الوظيفي للى العاملين بحمامات السباحة في المؤسسات الرياضية بمحافظة اسوان r- ضرورة المكاشفة والمصارحة مع العاملين والتي تعد مدخلاً مناسباً لتحسين

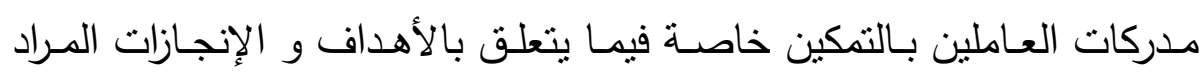
تحقيقها ومستويات الأداء المطلوبة.

ع - زيادة مكافآت وحوافز العاملين بحمامات السباحة في المؤسسات الرياضية

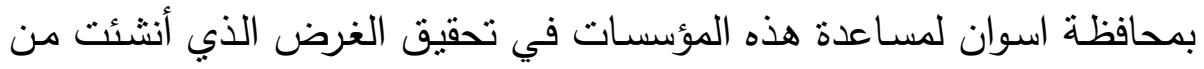
أجله وهو تحقيق النمو الثامل والمتزن للفرد من خلال الخدمات الرياضية التي تقدمها هذه المؤسسات.

0- إتاحة الفرصـة لدى الأفراد العـاملين للشعور بأهميـة وظيفتهم لمـا لها من علاقه بالاداء الوظيفى للعاملين بهذه المؤسسات.

ج- ضـرورة التطبيق الناجح لتمكين العاملين عن طريق غرس التقة المتبادلة من الإدارة العليا والمرؤوسين ونوفير الموارد والدعم الاجتماعي للعاملين وتحديد 
الأهداف المستقبلية وتكوين فرق العمل والاتصـال الفعـال والتدريب المستـر للعاملين.

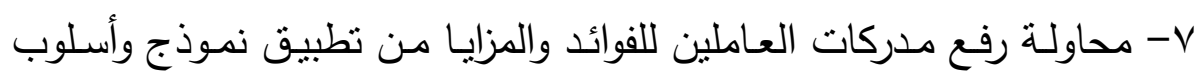
تمكين العاملين وأهميته لتحقيق النجاح فى الاداء الوظيفي للعاملين. 1- إتاحة الفرصـة بشكل أكبر للعاملين للمشـاركة فى اتخاذ القرارات وتمكينهم من السلطة.

\section{المراجع}

$$
\text { أولاً : المراجع العربية: - }
$$

أسـعد أحمد: أثر الثقافة التنظيمية على مستوى الأداء الوظيفي، التهاء

رسـالة ماجستير غير منشورة، كلية التجارة، الجامعـة الإسـلامية

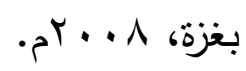

ץ-جمال محمد علي: الحديث فى الإدارة الرياضية والإدارة العامة، مركز الكتاب للنشر، الطبعة الثانية، 1 ، . rم.

r-خوله خميس عبيد: أثر الثقافة النتظيمية على تمكين العاملين - دراسة تحليلية على المصارف الأجنبية والعربية بدولة الإمارات العربية المتحدة،

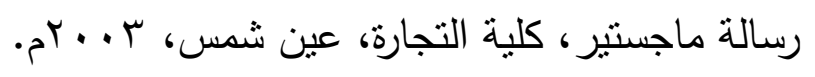

لاويـة محمــا: إدارة المـوارد البشـرية، المكتب الجـامعي الحديث،

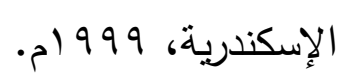

0 - رحساب على: دراسـة معوقات تطبيق مفهوم إدارة الجودة الثـاملة بحمامات السباحة في المؤسسات الرياضي بمحافظة الإسكندرية،

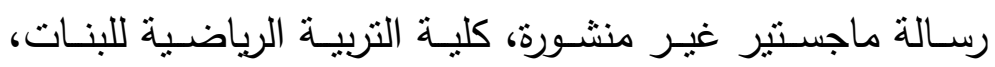

$$
\text { جامعة الإسكندرية، ع . . بم. }
$$




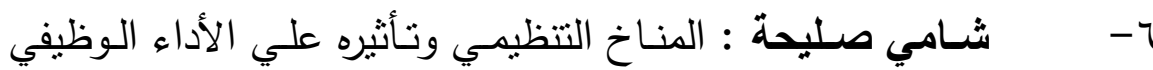
للعاملين، كلية العلوم الاقتصادية والتجاريـة وعلوم التيسر ، جامعة ولية

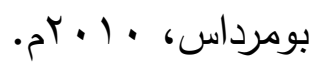

عادل مكي: "الإدارة بتمكين العاملين وأثزها على الرضا الوظيفي بحمامـات السـباحة يالمؤسســات الرياضـية"، المجلــة العلميـة المتخصصة، كلية التربية الرياضية، جامعة أسيوط، 9 . . ب م. عبد الله الطجم : قياس العوامل المؤثرة على وظائف جماعات $-\Lambda$ العمل فى المؤسسـات العامـة السـودية ، مجلـة العلوم الإداريـة ،

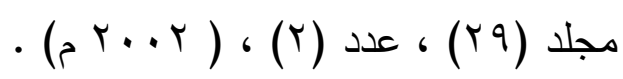
عبـــ الله الكنـــري: أثنر العدالــة التتظيميـة على فاعليـة الأداء الوظيفي (بالتطبيق على أعضاء هيئة التدريس بجامعة الكويت)، رسالة ماجستير غير منشورة، كلية التجارة، جامعة عين شمس، מ عصــام بـــدوى: موسـوعة التنظـيم والإدارة فـى التربيـة البدنيـة والرياضية، دار الفكر العربي، القاهرة، ا. +.بم.

عصسام حلمس، صسبرى عمـر : الإدارة الفنية بحمامـات السباحة،

منشاة المعارف، الإسكندرية، 999 (م.

عطيـة حسين أفندي: تمكين العـاملين مدخل للتحسين والتطوير

المسـتمر ، مجلــة البحـوث والدراسـات، المنظمــة العربيـة للتنميـة

$$
\text { الإدارية، جامعة الدول العربية، القاهرة، ب +. rم. }
$$

rا - محمد الحماحمي : الترويح المائي الفلسفة والتسويق، ط ا، مركز الكتاب للنشر ، القاهرة، ع . - بام. 
؟ ا- محمـ الـريس: أثر مقاومـة التغير علي فاعليـة الأداء الوظيفي بالتطبيق علي شركة العين لتوزيع الكهرباء والماء بدولة الإمارات

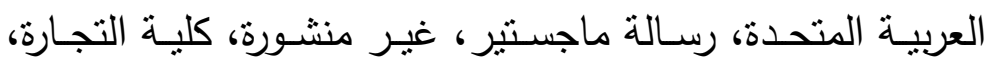
جامعة عين شمس، 0 . . برم. محمـــ الصـيرفي: إدارة الأفـراد والعلاقـات الإنسـانية، طا ا، دار $-10$ قنديل للنشر والتوزيع، عمان، r +. r بم.

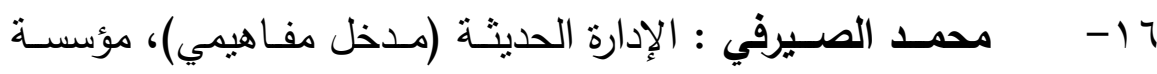
حورس الدولية، القاهرة، ع +. بrم. محمد عبد العظيم: خطة مقترحة لإدارة المؤسسات الرياضية وفقاً للأهداف التسـويقية، رسـالة دكتوراه، غير منشـورة، كليـة التربيـة الرياضية، جامعة أسيوط، 7 . . بـم.

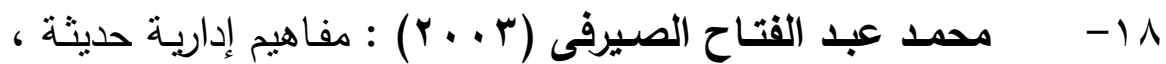

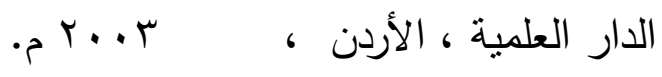
محمود نبيه: مقدمة فى السباحة والإنقاذ وإدارة الحمامات، طوخى ، مدرد $\ddot{a}$ للطباع

$$
(ت-ب)
$$

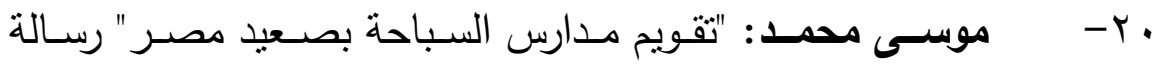

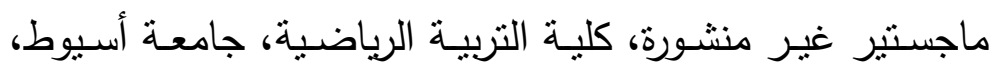
.

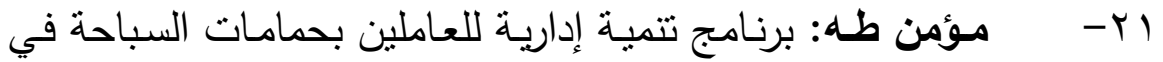
ضوء التحليل الوظيفي والقدرة التسويقية التتافسية، رسالة دكتوراه غير منشورة، كلية التربية الرياضية، جامعة أسيوط، I 1 • بم. 
r T - مؤمن طهه: تطبيق أسلوب الفجوة لقياس جودة الخدمة بحمامات

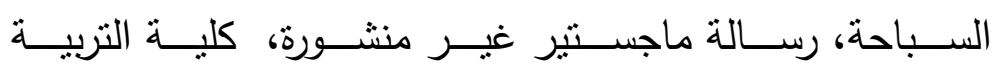

$$
\text { الرياضية،جامعة أسيوط، V +. - rم. }
$$

rr- - نانيس عبد الحافظ: علاقة ضغوط العمل بفاعلية الأداء الوظيفي للمرأة العاملة، دراسة تطبيقية علي كليات جامعة القاهرة الكبرى، رسالة ماجستير ، غير منشورة، كلية التجارة، جامعة عين شمس،

$$
\text { ثانياً: المراجع الأجنبية:- ب }
$$

24- James C Becker: The important of individual performance from the perspective of gnome and ongoingational performance effectiveness "small group research" vol 32 ،2001.

25- Adel Meky:" Ways of marketing of the water sport in the Arab Republic of Egypt", European Collge of Sport Science, Lausanne-Switzerland July 5- 8, 2006.

26- Bennis,R Townsend : "Reinveting Leader Ship" newYork, willian morrow (1995).

27- Daft,Richard L, organizational Theory and Design.3th ed., Tomson-south-western,ohio.(2003).

28- kaller: The link Between Organization Justice And Job Satisfaction Academy of Management Review ، vol.45 2002. 
29- Kim K \& J.H. Park: "Integrating Distinctive Manufacturing Competence Globally: Its Effect on Business Performance", Multinational Business Review, VOL, 8 , on 1, Spring 2000.

30- Simons, RobertControl In An Age Ideology, Organization Studies, Vol.(123),No.(3) ,(1995),. 